\title{
Innovation and practice of teaching methods based on the new curriculum standard
}

\section{Cheng Tieli}

\author{
Xijing University, Xi'an, 710123, China
}

Keywords: new curriculum, sports, teaching methods

\begin{abstract}
The new curriculum standard is new no matter from the target requirements or the structural system, it contains the concept of quality education and makes the sports teaching to get a significant innovation and breakthroughs. In this paper, we discussed in depth about the role transformation of the physical education teachers and the innovation of teaching methods in order to provide some new ideas in the role adjustment of teachers and keeping pace with the new curriculum under the new situation. In the process of learning students' learning style has personality traits and independence, we should reverse the past phenomenon that with too much emphasis on accepting study, allowing diverse learning styles. This paper focuses on the promoting of students' individual character development, enhancing the attraction of the physical education, making physical education be a course that the students favorite to participate in. Introduction.
\end{abstract}

\section{Introduction}

The traditional pattern and method of physical education teaching restricted the development of the students' individuality causing the boredom to the physical education. Schools and teachers often only pay attention to students' mastery of sports skills, train athletes with requesting for athletics, ignoring the students' personality development and eliminating the student's creative ability. That is not conducive to the comprehensive and healthy development of students. Practice has proved that the success of many great men and the invention of scientists have a close connection with individual character. The most familiar scientist to the students Thomas Edison had experienced countless failure when he invented the light bulb, because of strong personality, he finally brought light to the world. The 21st century is a era of the pursuit of "personality", especially, the modern families in the majority are with only one child, forming many complex factors the personality itself, so physical education teachers cannot simply understand the "personality", but to analyze from the angle of teaching and students' personality development, to find their common characteristics. With the implementation of the new curriculum standard, we took a comprehensive and detailed reform to the physical education teaching. Our sports teachers should seize this opportunity to improve the teaching content and teaching method, pay attention to students' individual differences, develop students' individual character, make the student to establish the idea of lifelong sports. The class is our practice stage, how to promote personality development of students? We should think and explore with all the aspects. 


\section{The understanding of physical education teaching mode under the new curriculum idea.}

\subsection{Correctly understand the change of name and nature of the course.}

The new curriculum is not a comprehensive course combined with the traditional physical education and the original health education, but it emphasizes on that the fundamental purpose of physical education is to promote students' physical and mental health development, literally carry out the "health first" guiding ideology, pay attention to that how students through physical activity to realize the goal of health. What it pays attention to is how to make students not only enhance physical fitness and master basic sports skills, but also to get comprehensive development through the course of teaching. New curriculum emphasizes that combine the teaching and the cultivation of people closely, organically.

\subsection{Understand the basic conception of sports teaching mode in depth.}

Teaching mode are the relatively stable teaching procedures and strategy system of methods based on certain teaching ideas and teaching rule, which in the process of teaching we must abide by. Compared with other disciplines teaching mode, physical education teaching mode not only has the general characteristics of the teaching mode, but also has the characteristics of sports teaching. We summarized them, the sports teaching mode is defined as: the typical and stable teaching style based on sports teaching thoughts and teaching laws, and the structure of physical education teaching process and the corresponding teaching method system.

\subsection{Correctly grasp the structural elements of physical education teaching mode under the} new curriculum.

(1) Sports teaching ideas.

Physical education teaching thought is a theoretical basis of physical education teaching mode, enable people to understand the cause and effect of teaching mode. For example, the happy sports teaching mode, is based on "health first" guiding ideology, has tried to build curriculum structures such as skills, cognition, emotion, behavior, fusion of knowledge, skills and methods of the students' physical and mental development.

(2) The teaching goal.

Teaching model is designed to achieve a specific teaching goal. Teaching aim is the core factor in teaching mode, determines the operating procedures and policies, etc of the mode. Physical and health education classroom teaching mode must effectively to promote students to develop in five areas of participation in sports, sports skills, physical health, mental health and social adaptation.

The implementation of physical education and health curriculum standard makes a great changes in the structure of the elements of sports education mode, thus changes the sports teaching mode.

\section{The innovation and practice of the new curriculum standard physical education teaching methods.}

\subsection{Stimulate students' interest in sport, form a pleasant classroom atmosphere.}

Sports interest is psychological tendency that people want to positive and priority engage in the activities, it is the need of participation in sports activities linked intention activity, is the most direct manifestation of personality. Great educator Confucius has claimed: "People who know it is better than who work on it, who work on it is not as good as who loves it." Where does interest come from? Interest comes from life experience. Each student has an independent personality, its expression is varied. Especially in physical education, students bring life experience into practice, and personality factors are often restricted the performance way. For example the hyperactivity 
children are very interested in any physical activity, but their organizational discipline consciousness is not strong; the consciousness to participate in the collective activities of introverted children is weak; Children who decide on interest choose the physical activity to take part in only by personal interest. I taught in grade 6, there is a very naughty and playful child, he could not sit in the classroom, had no class collective consciousness, many teachers had no idea to him. After several contacts, I found that he had strong self-esteem, relentlessness, liking showing in front of classmates. So I actively encouraged him to participate in the management of classroom, let him in charge of sports equipment configuration and recycling, transform his activities interest, cultivate the consciousness of servicing for students. In persuading education at the same time, illustrate the importance of the equipment management work and the teacher's importance, to be qualified for this job should do the first model of the other students in class, establish credibility. After a period time of adapting, his ability to organize and activities had obviously increased, and the equipment management work is done in an orderly way. Comprehensive above factors, I suggest that teachers should establish a relation of cooperation and interaction with students on the basis of understanding students, treat each student equally and sincerely, try to meet the interest needs of the vast majority of students and make sports classroom be the showcase of students' interest.

Secondly, to build a relaxed, pleasant classroom atmosphere, set corresponding situation in view of the teaching content. Situational teaching is an important means of cultivating students' healthy personality and the correct outlook on life. Especially for the lower section of students, with stronger curiosity for knowledge, their interest is easier to inspire and transform. Therefore teachers' choosing content should be diversified, starting from the students' mental and life, choose more children, fun sports, use different teaching methods to guide and change, let the student to open their mind, get into the context set by teacher, motivate students initiative to participate in sports activities, and in practice, experience the infinite happiness the physical education learning brings.

\subsection{Change ideas, exert students' subject consciousness.}

As to who is the main problem, the teacher is authoritative, the center of teaching is a teacher, although this view is not dominant, but our teachers in the teaching activities are often ignored the problem. The main body of cognitive activities is students, only by the student's own activities can they accept all the influence of education the teaching. Teachers are dominant, the organizers, he plays a role of regulation to the whole class, only by teachers can achieve exchange and communication of information. The students view of subject teaching is: there are no bad students but only differences between students from each other. We pay attention to the individuality development of student, promote personality development, more to understand the personality development, personality development is not that the teachers give their personal teaching according to each student's willingness and what students like to learn, but to according to the psychological characteristics of students, respect their body feeling and make it play the main role. Especially in our vast rural school, the ground equipment is relatively backward, many ways still can't satisfy the needs of student activities, and many of the physical education teachers must to part-time several courses, so the teachers cope with physical education, talking too much, does not pay attention to the students' feelings, let alone take the student as the main body of teaching. With the constant progress of the society, many of our knowledge can not adapt to the development of modern teaching. So teachers should change ideas, in the class must put the students to the main body position, enlighten and guide by differences, study independently, access knowledge, from really experience emotion of grapping and participating in knowledge personally, produce a pleasant emotional experience, look the physical education learning as a kind of tension and enjoyable activities, thus consciously actively devoted in learning. 
Take sports education into daily life, teachers need to change ideas in the teaching of applications, aside from the bondage of traditional education model, starting from the goal of improve student health, seriously analyze the characteristics of the teaching material, carefully study teaching methods, meet the most needs of the students, teach according to their aptitude, fully display their individual talents, encourage students to consciously and actively for creative learning. In a using of light practice class of middle section grade, I put the question to students that what kind of practice equipment should we use, students were very interested in my question, the students solve the problem for me using the most common plastic bags and paper in life. So in class, I let go of the hands and feet, let students themselves to imagine, design and practice freely, they feel that the long plastic bag like the tail, extracted the different forms of grasp tail games; a newspaper in a plastic bag like a charge, completed the most interested fighting games to after communicated with me. I have to admire the using of playing the subjectivity of the students. It is important to note that the personality development what we are after is on the perspective of the whole teaching, students' overall development oriented, activities to promote personality development as a whole, but it is not to extreme by student indulges, to take "the sheep type" teaching. A good sports teacher should fully understand the difference between students and fully understand the teaching goal, fully explore the value of an object, fully use teaching methods, rather than using teaching stage to show incisively and vividly of self-expression.

\subsection{Establish equal relationship between teachers and students, pay attention to students' innovative ability.}

Sports teaching is a practice class as the main body of subject, in the teaching process, teachers and students practice, games, game together, hardships together, share the joy of victory. I think the students' feeling is the true feelings, the assessment of students is the best choice. The Angle of the students in our physical education teachers should be used to look at ourselves, constantly improve our own quality, because teachers' own quality is the necessary condition to establish good relationship between teachers and students. Teachers' and students' status are equal, both between the education of teachers' teaching and students' learning. Physical education teachers must set up the correct student view, democratically and equally cooperate and communicate with students, rather than on high and command the "cramming" and "force-feeding" teaching, such children are just being forced to accept, there is no independent opinion and personalized feedback. Only respect the student individuality development the teachers can win full trust and respect, so as to enhance their personality charm, to speed up the students' understanding and mastering of knowledge, form the best education situation. Only in this way can PE teachers stimulate students' creative thinking, make the students independent innovation, further promote the development of personality.

\section{Conclusion}

The world is changing all the time, sports is a science from innovation and development. Secretary Jiang once said: innovation is the soul of a nation's progress, is the driving force in a country's development. In the sports teaching, the innovation and personality development is inseparable, the personality development usually decides the improvement of the innovation ability, every student has an independent personality, everyone has a different view of the problems, their feelings and needs is likely to be what we ignored in our teaching, every child around us is a great treasure. In physical education teaching, physical education teachers should fully tap the potential of students, give the appropriate evaluation and encouragement, and activate the creative thinking of students. To renovate their own teaching method, to establish a new relationship between teachers and students, respect students' subject status, satisfy their curiosity, learning needs and interests, give full play to the spirit of their search. Students observe things and analyze problems 
from different angles, tend to provide human nature to change more, teachers should respect and adopt the idea of students, make students to obtained innovation with the independent, and innovation ability enhancement effects to promote the development of personality. In specific sports teaching process, allow students to design the game or improve the method of game, let students to use and improve the knowledge in the whole process. I once let students to experience the small ball game in the small ball class, they created a dozen free practice, like catching and throwing, all kinds of ball, passing and so on, and we selected several games into the game teaching, students are learning in play and it is a very good exercise. This lesson also gave me a lot inspiration, we must be good at finding the new knowledge, new things and new problems contained nearby, in fact, our children are in constant development and innovation every day. We should to correctly understand students individual differences objectively and different needs, let our teaching be geared to all the students, make students to get perfect personality and personality, let every child be the role of class lively.

\section{References}

[1] Li Jia-hou . The management and application digital campus construction and application of new technology training "course" of the development. Shanghai normal university press. 2014.

[2] The application of flipping class in information technology teaching in high school. The information technology education in China. 2013 (12).

[3] Design of flip case classroom teaching based on the interactive whiteboard. 2013.

[4] The application of the "flip" model in the computer foundation teaching. Reading and writing (education teaching research). 2014 (7).

[5] Research on learning support services for flipping class. China distance education (comprehensive). 2014 (5). 